\title{
Pengembangan Ekowisata Berbasis Masyarakat Di Desa Pemo Taman Nasional Kelimutu Kabupaten Ende
}

Yudha Eka Nugraha a,1, Yasinta Etrisia Siti a,2

1yudhaekanugraha@gmail.com,2 yasintaetrisiasiti@gmail.com

a Politeknik Negeri Kupang, Nusa Tenggara Timur

\begin{abstract}
This research is concerned to elaborate new potential tourist attraction in Desa Pemo Taman Nasional Kelimutu. Desa Pemo has special attraction that is authentic and unique related with nature and culture. The method used is qualitative with descriptive approach. The data collected through in depth interviews with Head of Desa Pemo, Representative of Taman Nasional Kelimutu management, community member, and tourist. The data analyzed using IFAS EFAS analysis and SWOT analysis. The result shows that Desa Pemo has a authentic and unique attraction from the beauty of nature, culture, and hospitable community. Desa Pemo is classified in Quadrant I which means needs to take advantage of external opportunities, overcome internal weaknesses and avoid external threats.
\end{abstract}

Keywords: Development Strategy, SWOT Analysis, Community-Based Ecotourism

\section{PENDAHULUAN}

Pertumbuhan ekowisata yang pesat dalam beberapa tahun terakhir disebabkan oleh negara-negara yang mempromosikan ekowisata. Fenomena ini terjadi karena bertumbuhnya pasar ekowisata di berbagai negara. Promosi ekowisata dilakukan dalam rangka menarik minar wisatawan untuk memilih serta memperoleh manfaat dari aktivitas ekowisata yang memberikan dampak secara langsung kepada masyarakat pengelola. Sejalan dengan hal tersebut, World Travel Tourism Council (WTTC), menyatakan bahwa pertumbuhan ekowisata rata-rata pertahun selalu naik dengan presentase $8,1 \%$. Hal ini diperkuat dengan jumlah wisatawan internasional yang berminat dengan kegiatan ekowisata terutama di Indonesia tahun ini peningkatan sampai di angka $14,2 \%$ atau melebihi pertumbuhan wisatawan domestik yang hanya sebesar 6,3\%. Angka pertumbuhan ini diklasifikasikan tinggi bila dibandingkan dengan pertumbuhan ekonomi berbagai negara di dunia. (Nugraha, 2019).

Terdapat banyak destinasi ekowisata bila berbicara mengenai Republik Indonesia. Salah satu destinasi ekowisata yang ada di Indonesia adalah daya tarik ekowisata di Tanam Nasional Kelimutu. Pada awal pengelolaannya, Taman Nasional Kelimutu (TNK) dikerjakan oleh pengelola setingkat unit kerja yang tercantum dalam keputusan Menteri Kehutanan Nomor 185/KTPS-11/1997 tentang organisasi dan tata kerja Balai Taman Nasional dan Unit Taman Nasional. Pengelola ini adalah organisasi unit yang menamakan diri sebagai Taman Nasional Kelimutu. Selanjutnya, pengelolaan Taman Nasional didasarkan atas keputusan Menteri Kehutanan nomor 6186/KTPS-11/2002 disahkan secara resmi tanggal 10 Juni 2002 mengenai tata kelola Kerja di Balai Taman Nasional Kelimutu.

Taman Nasional Kelimutu (TNK) yang sudah terkenal dengan danau tiga warnanya, memiliki potensi alam yang indah dan berada disekitar kawasan konservasi bernama Hutan Sokoria. Hutan ini memiliki ekosistem flora dan fauna yang beragam. Keberagaman inilah yang menjadi salah satu faktor kuat yang melatarbelakangi sehingga kawasan Hutan Sokoria tepatnya pada tahun 1982 diusulkan dan pada tahun 1992 ditunjuk, serta pada tahun 1997 ditunjuk sebagai salah satu kawasan konservasi dan pelestarian berbasis alam yang dikelola sebagai sebuah Taman Nasional bernama TN Kelimutu. Secara administratif TN Kelimutu dikelilingi oleh lima wilayah setara Kecamatan yaitu: Kecamatan Ndona, Kecamatan Wolojita, Kecamatan Detusoko, Kecamatan Ndona Timur dan Kecamatan Kelimutu

Dalam salah satu kecamatan tersebut terdapat sebuah desa yang berada di dekat Taman Nasional Kelimutu yang memiliki potensi autentik dan unik namun belum dikembangkan. Seperti contoh, potensi yang ada di Desa Pemo selain atraksi alam danau tiga warna Kelimutu terdapat juga pembuatan kain tenun oleh mama-mama setempat. Sayangnya, potensi kegiatan wisata yang terbuka lebar ini belum dioptimalkan oleh pihak-pihak pelaku pariwisata. Padahal data menunjukkan bahwa kunjungan turis ke TN Kelimutu terus meningkat setiap tahunnya, terutama turis domestik.

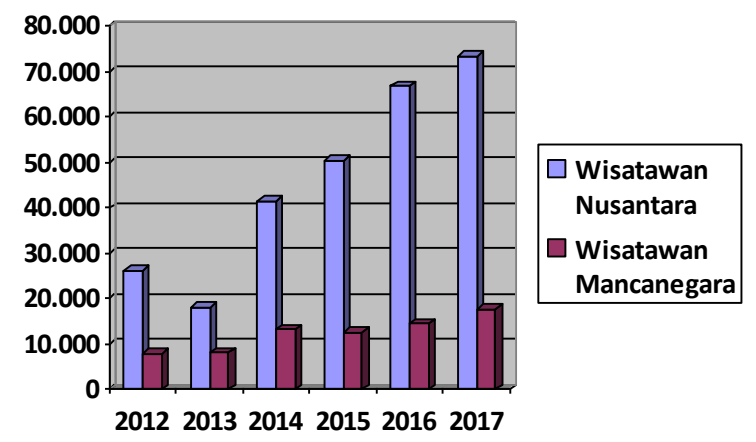

Tabel 1. Data kunjungan TN Kelimutu (Sumber: data Balai TNK)

Dari tabel 1 diatas dapat dilihat bahwa pengunjung yang berkunjung ke TN Kelimutu mengalami peningkatan dari tahun ketahun. Peningkatan kunjungan wisatawan seharusnya memberikan dampak positif terutama dari segi ekonomi untuk penduduk lokal yang berada di kawasan TN 
Kelimutu. Namun, hal ini tidak demikian, tidak merasakan dampak yang signifikan terhadap kedatangan wisatawan tersebut. keuntungan ekonomi masyarakat lokal harus diutamakan. Dalam pengelolaannya harus mampu memberikan keuntungan sosial ekonomi secara berkelanjutan serta mengikut sertakan partisipasi aktif masyarakat lokal dan wisatawan didalamnya. Berdasarkan kenyataan ini maka patut dipertanyakan bila kemiskinan dan kehidupan tidak layak yang dialami oleh masyarakat di kawasan TNK tersebut bisa dikarenakan oleh belum adanya implementasi prinsip-prinsip ekowisata khususnya pada praktik partisipasi aktif masyarakat lokal bersama wisatawan di dalamnya. Kenyataan ini sesuai dengan hasil studi Nistyantara (2011) yang menyatakan bahwa pengelolaan TNK masih tetap mempertahankan paradigma pemeliharaan terpusat (preservationist) dan penentuan keputusan kebijakan yang terpusat di Balai TNK. Hal ini menyebabkan seringkali terjadi keputusan yang tidak selaras antara pengelola TNK dan kebutuhan penduduk lokal di TNK. Penelitian ini mengamati bahwa pengembangan yang sejauh ini dilakukan belum memberikan implikasi pada kesejahteraan masyarakat Desa Pemo yang tinggal di sekitar TN Kelimutu. Sehingga pengembangan ekowisata berbasis masyarakat menjadi salah satu rumusan untuk memetakan potensi sekaligus arah pengembangan agar pengelolaan daya tarik di Desa Pemo lebih terarah. Terutama dalam kaitannya untuk menguatkan posisi masyarakat dalam pengelolaan pariwisata setempat.

\section{METODE PENELITIAN}

Penelitian mengenai pengembangan ekowisata ini menggunakan metode kualitatif. Metode kualitatif dipilih sebagai upaya mengungkapkan gejala-gejala sosial secara mendalam dan akan digali secara mendalam melalui interpretasi peneliti dan pengalaman yang dirasakan oleh masyarakat (Sugiyono, 2015; Nugraha, 2019). Keunggulan metode kualitatif adalah untuk memperoleh sudut pandang yang lebih alami berdasarkan pengalaman masyarakat dan mendalaminya sebagai suatu indikator yang terperindi dalam kondisi masyarakat (Lewis, 2003 dalam Dewi 2013).

Kajian teori yang mendasari penelitian ini yakni menurut Denman (2001) dalam Nugraha (2019) menjelaskan bahwa ekowisata berbasis masyarakat dapat membantu memelihara penggunaan sumber daya alam dan penggunaan lahan yang berkelanjutan. Beberapa syarat dasar dalam pengembangan ekowisata berbasis masyarakat adalah:

1. Lanskap atau flora dan fauna yang dianggap menarik bagi para pengunjung.

2. Ekosistem masih dapat menerima kedatangan pengunjung dalam jumlah tertentu tanpa menimbulkan kerusakan.

3. Komoditas lokal yang sadar akan kesempatankesempatan potensial, resiko dan perubahan yang akan terjadi serta memiliki ketertarikan untuk menerima kedatangan pengunjung.

4. Adanya struktur yang potensial untuk pengambilan keputusan komunitas yang efektif

5. Tidak adanya ancaman yang nyata dan tidak bisa dihindari atau dicegah terhadap budaya dan tradisi lokal

6. Penaksiran pasar awal menunjukan adanya permintaan yang potensial untuk ekowisata dan terdapat cara yang efektif untuk mengakses pasar tersebut. Selain itu juga harus diketahui bahwa pasar potensial tersebut tidak terlalu banyak menerima penawaran ekowisata.

Dalam pengembangan ekowisata dengan melibatkan masyarakat lokal relatif mudah dilaksanakan karena memiliki beberapa keunikan, yaitu:

1. Jumlah wisatawan berskala kecil sehingga lebih mudah di koordinir dan dampak yang akan ditimbulkn terhadap alam relative kecil di bandingkan pariwisata massal.

2. Ekowisata berbasis masyrakat lokal memiliki peluang dalam mengembangkan atraksi-atraksi wisata yang berskala kecil sehingga dapat dikelola dan lebih mudah diterima oleh masyarakat lokal.

3. Dengan peluang yang dimiliki masyarakat lokal dalam mengembangkan objek-objek wisata yang ada disekitarnya memberikan peluang lebih besar pula dalam partisipasi masyarakat lokal dalam pengambilan keputusan.

4. Memberikan pemahaman pentingnya keberlanjutan budaya (cultural sustainability) serta meningkatkan penghargaan wisatawan terhadap kebudayaan lokal.

Penelitian dilakukan di Desa Pemo Taman Nasional Kelimutu Kabupaten Ende Provinsi Nusa Tenggara Timur. Data yang dipergunakan dalam penelitian ini bersumber dari data primer dan data sekunder. Data primer diperoleh dengan metode wawancara mendalam dengan pengelola Taman Nasional Kelimutu, tokoh masyarakat, kepala desa dan juga wisatawan. Total informan yang berpartisipasi dalam kajian pengembangan berjumlah 4 orang. Penentuan informan dipilih melalui metode snowball sampling dengan memperhatikan jumlah wakil masyarakat setempat. Selain data primer, data sekunder juga dibutuhkan untuk meningkatkan kualitas kajian dalam penelitian ini. Data sekunder didapatkan dari laporan yang diterbitkan pemerintah setempat, buku, website pemerintah, jurnal terkait, koran, dan sumber relevan lainnya. Semua data yang terkumpul kemudian dianalisis dengan analisis IFAS EFAS dan SWOT (Rangkuti, 2006, Sunarjaya,2019) analisis untuk memperoleh deskripsi terperinci secara lengkap mengenai kondisi Desa Pemo, sebagai dasar perumusan strategi pengembangan.

\section{HASIL DAN PEMBAHASAN}

Gambaran Umum Desa Pemo Kecamatan Kelumutu di Kabupaten Ende

Pada mulanya Desa Pemo adalah Desa pemekaran dari Desa Induk Woloara sesuai dengan Peraturan Daerah yang merupakan wilayah dari Kecamatan Kelimutu Kabupaten Ende. Sejak tahun 1964/1965 masih disebut dengan Kapitan. Pada Tahun 1995 muncul sebuah komitmen atau persetujuan bersama para Mosalaki, Tua Adat, dan Tokoh Masyarakat dari Seluruh wilayah menyepakati dan akhirnya memilih sebuah Nama Desa yaitu Pemo. Jumlah penduduk Desa Pemo seluruhnya 375 jiwa dan separuh penduduk lokal Desa Pemo memiliki pekerjaan bertani, di tanah yang memiliki luas wilayah 9,38 $\mathrm{km}^{2}$ yang terdiri dari 3 dusun yaitu dusun Nua Ria, dusun Wolomuku, dan dusun Sigo. Desa Pemo juga berbatas langsung dengan beberapa Desa lainnya yaitu : 
Vol. 8 No 2, 2020

Tabel 2. Batas Desa Pemo

\begin{tabular}{|l|l|l|}
\hline BATAS & DESA & KECAMATAN \\
\hline UTARA & WOLOARA & KELIMUTU \\
\hline SELATAN & $\begin{array}{l}\text { DESA } \\
\text { TENDA }\end{array}$ & WOLOJITA \\
\hline TIMUR & $\begin{array}{l}\text { RINDI } \\
\text { WAWO }\end{array}$ & WOLOWARU \\
\hline BARAT & TOBA & NDONA TIMUR \\
\hline
\end{tabular}

Sumber data: Kantor Desa Pemo, 2019

Desa Pemo memiliki iklim yang unik dalam hal keberhasilan bertani bagi masyarakat. Iklim memegang peranan penting dalam pertumbuhan dan perkembangan tananman. Iklim juga dapat membuat wisatawan betah dengan suhu udaranya yang begitu dingin. Desa Pemo berada di bagian Barat ibu kota Kecamatan Kelimutu, dengan ketinggian antara 960 mil dari permukaan laut (dpl), secara geografis kontur alam di Desa Pemo terdiri dari lereng dan perbukitan dengan curah hujan pertahun terjadi sekitar 4-5 bulan hujan dengan suhu harian rata-rata $25^{\circ} \mathrm{C}$ s/d $30^{\circ} \mathrm{C}$.

\section{Potensi Daya Tarik Ekowisata Berbasis Masyarakat Desa Pemo Taman Nasional Kelimutu Panorama Bentang Alam, Flora, dan Fauna}

Kawasan Dasa Pemo memiliki panorama alamnya yang indah dengan hamparan hutan lembah, lautan, dan alam perbukitan yang membentang luas. Keindahan alam juga didukung oleh keadaan suhu udara yang sejuk membuat wisatawan betah untuk berlama-lama. Selain itu lingkungan sekitar dan keadaan alam sangat mendukung terciptanya kawasan wisata dengan pemanfaatan potensi perkebunan penduduk maupun tanaman hutan sebagai alternatif pengembangan kesejahteraan masyarakat desa selain sanggar budaya.

Kawasan Taman Nasional Kelimutu (TNK) di Desa Pemo memiliki beberapa daya tarik wisata alam lain yang dapat dikunjungi seperti perkebunan kopi milik warga. Kebun kopi ini unik karena pada dasarnya wilayah di provinsi Nusa Tenggara Timur mayoritas merupakan lahan kering sedangkan berbeda dengan di Desa Pemo, suhu yang sejuk membuat kopi bisa tumbuh dan menjadi salah satu ciri khas Flores dikenal dengan sebutan Kopi Flores. Daya tarik ini dapat menjadi potensi daya tarik wisata alternatif berbasis ekowisata selain danau tiga warna.

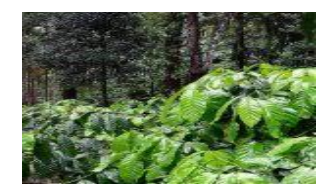

(a)

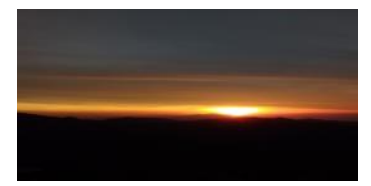

(b)
Gambar 2. Potensi Ekowisata dan Daya Tarik Wisata Alam Desa Pemo (a)Kebun Kopi (b) Sunset Sumber: Dokumentasi Pribadi

Kawasan Taman Nasional Kelimutu (TNK) Desa Pemo merupakan pertemuan antara areal hutan yang luas, areal pertanian dan perkebunan yang merupakan milik masyarakat setempat. Selain kebun kopi, di desa ini juga dapat ditemukan jenis tanaman lain diantaranya: kemiri, jambu mente, jagung, padi, bambu, pisang, kacang-kacangan dan lain-lain.
Selain berbagai varietas flora yang ditemukan, di Desa Pemo juga terdapat beberapa jenis fauna yang ditemui disini yaitu berupa babi hutan, burung garugiwa, monyet, ayam hutan, serta hewan ternak seperti babi, sapi, kuda, kambing, anjing dan ayam, beberapa diantaranya merupakan jenis hewan peliharaan masyarakat Desa. Keanekaragaman jenis flora dan fauna di Desa Pemo dapat dimanfaatkan sebagai alternatif kegiatan wisata berbasis ekowisata alam.

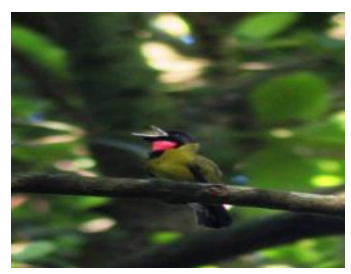

Gambar 3. Fauna khas burung Garugiwa

Sumber: Dokumentasi pribadi

Selain potensi alam, secara geografis, letak daya tarik wisata budaya di Desa Pemo berdekatan dengan wisata budaya yang lain yang berada di sekitar Desa Pemo. Seperti wisata buatan yang ada di Desa Waturaka. Pasar tardisional Nduaria, penginapan Sa'o Ria, persawahan Waturaka dan lainnya. Daya tarik wisata ini berdekatan dengan Desa Pemo dan dapat dikunjungi karena lokasinya yang berdekatan.

\section{Keunikan dan Keaslian Budaya di Desa Pemo}

Daya Tarik Wisata danau tiga warna, sanggar budaya dan rumah adat yang ada di Desa Pemo Taman Nasional Kelimutu (TNK) menyuguhkan atraksi budaya yang bebeda dangan daya tarik wisata serupa lainnya, dengan menyajikan proses pembuatan rumah adat, alat musik dan kain tenun, pembuatan alat musik dari kulit binatang seperi sapi atau kerbau dijadikan gendang, seruling dari bulu, gong dibuat dari tembaga, memainkan alat musik ketika pada acara ritual adat atau pembuatan rumah adat dan wisatan yang datang berkunjung. Proses pembuatan rumah adat, dilakukan 5 (lima) tahun sekali yang ditandai dengan penggantian atap rumah adat dari daun alang-alang.

Sejauh ini, Desa Pemo sudah memiliki daya tarik budaya yang sangat diminati oleh wisatawan yang berkunjung. Kegiatan tersebut adalah proses membuat tenun ikat asli NTT.

Proses pembuatan tenun ikat mulai dari pengolahan kapas mentah menjadi benang, proses pewarnaan sangat tradisional dengan memanfaatkan tumbuhan alami sebagai pewarna, sampai dengan proses penenunan yang semuanya dilakukan secara manual atau tradisional. Wisatawan yang datang berkunjung dalam bentuk rombongan ataupun perorangan, biasanya sudah melakukan reservasi jauh sebelum kedatangan. Bagi wisatawan yang belum pernah melakukan pemesanan paket wisata, semuanya akan tetap dilayani dengan baik oleh anggota sanggar budaya.

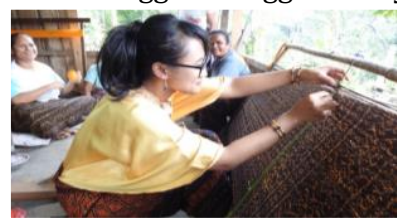

Gambar 4. Wisatawan sedang membuat tenun ikat di Desa Pemo

Sumber: Dokumentasi Pribadi 
Vol. 8 No 2, 2020

Adapun daya tarik wisata selanjutnya masih terkait dengan wisata budaya berbasis masyarakat yakni Ritual Adat bernama Upacara Pati Ka Du'a Bapu Ata Mata atau Pati Ka Ata Mata (memberi makan kepada arwah leluhur) yakni ritual adat memberi makan kepada orang yang sudah meninggal. Esensi yang dipercaya dalam melaksanakan ritual adat Pati Ka Du'a Bapu Ata Mata adalah sebagai ucapan syukur atas apa yang masyarakat menikmati selama setahun. Selain itu melalui kegiatan ini juga berfungsi sebagai pengingat untuk mendukung keberadaan ekowisata di TN Kelimutu agar selalu memelihara budaya setempat, menjaga kelestarian alam terutama burung endemic lokal yang terancam punah, dan arah pengembangan pariwisata yang hanya dilakukan untuk meningkatkan kesejahteraan masyarakat setempat.

Daya tarik selanjutnya yang berbasis budaya adalah rumah adat Desa Pemo, kesenian adat berupa tarian yang dilaksanakan selama prosesi ritual adat Pati Ka Ata Mata, dan pertunjukkan alat music dengan menggunakan Sato. Potensi sosial dan budaya lain yang ada di Desa Pemo diantaranya, cara hidup masyarakat setempat, cara bercocok tanam, tradisi dan karakterisitik masyarakat yang dapat menarik minat wisatawan dan menambah penyetahuan wisatawan akan seni budaya dari daerah yang dikunjungi.

\section{Keramahan Masyarakat Lokal dan Keterbatasan Fasilitas}

Keramahan masyarakat setempat, serta suasana kehidupan di Desa Pemo menjadi salah satu pemikat wisatawan untuk datang berkunjung. Hal ini dapat memberikan kesan yang baik bagi wisatawan sehingga berpeluang meningkatkan jumlah kunjungan wisatawan ke Desa Pemo. Keadaan fasilitas pendukung di objek wisata sanggar budaya juga menjadi kendala karena masih banyak fasilitas yang kurang seperti area parkir, toilet, dan tempat pertunjukan budaya yang belum ada. Kawasan wisata yang berada di desa pemo memiliki banyak kekurangan dalam hal fasilitas umum, seperti toilet yang belum layak dan memadai, belum adanya area parkir serta plang penunjuk jalan menuju desa pemo dan tempat pertunjukan budaya yang kurang memadai.

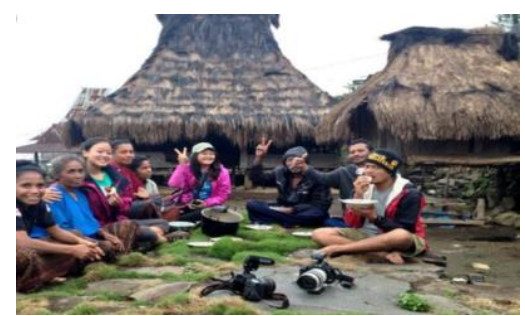

(a)

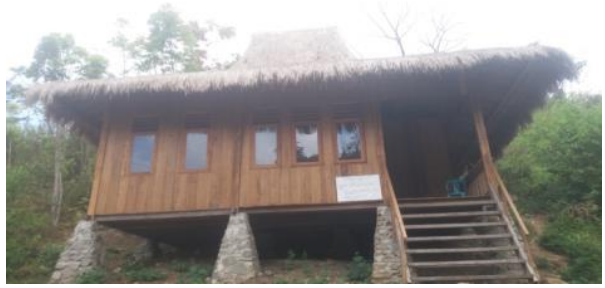

(b)

Gambar 5 (a) Keramahtamahan Masyarakat (b) Homestay

Tabel 3 Sintesa Faktor Kekuatan dan Kelemahan Desa Pemo Taman Nasional Kelimutu

\begin{tabular}{lcccc}
\hline Faktor-Faktor Strategi Internal & Bobot & Respo & B X R & Mean \\
\hline Kekuatan (Strengths) & & & & \\
\hline 1. Keunikan dan Keaslian Budaya & 0.42 & 4.00 & $0.42 / 4$ & 0.10 \\
\hline 2. Keindahan Panorama Alam & 0.34 & 4.00 & $0.34 / 4$ & 0.08 \\
\hline 3. Keanekaragaman Flora dan Fauna & 0.48 & 4.00 & $0.48 / 4$ & 0.12 \\
\hline 4. Keramahan Masyarakat Lokal & 0.42 & 4.00 & $0.42 / 4$ & 0.10 \\
\hline 5. Keamanan Desa Pemo & 0.24 & 4.00 & $0.24 / 4$ & 0.06 \\
\hline 6. Ketersediaan Amenitas berupa Homestay & 0.26 & 4.00 & $0.26 / 4$ & 0.06 \\
\hline 7. Iklim yang sejuk membuat wisatawan betah & 0.31 & 4.00 & $0.31 / 4$ & 0.08 \\
\hline Kelemahan (Weakness) & & & & 0.07 \\
\hline 1. Lemahnya kualitas SDM di bidang pariwisata & 0.28 & 4.00 & $0.28 / 4$ & 0.08 \\
\hline 2. Jarak tempuh yang jauh dari pusat kota & 0.30 & 4.00 & $0.30 / 4$ & 0.06 \\
\hline 3. Tempat makan dan minum yang kurang memadai & 0.22 & 4.00 & $0.22 / 4$ & 0.06 \\
\hline 4. Akses jalan yang rusak & 0.27 & 4.00 & $0.27 / 4$ & 0.07 \\
\hline 5. Kurangnya keterlibatan stakeholders & 0.24 & 4.00 & $0.24 / 4$ & 0.06 \\
\hline 6. Kegiatan wisata yang belum terstruktur & 0.23 & 4.00 & $0.23 / 4$ & 0.06 \\
\hline TOTAL & $\mathbf{4 . 0 0}$ & & & $\mathbf{1 . 0 0}$ \\
\hline
\end{tabular}

Tabel 4 Sintesa Faktor Kesempatan dan Ancaman Desa Pemo Taman Nasional Kelimutu

\begin{tabular}{llllc}
\hline Faktor-Faktor Strategi Eksternal & Bobot & Respo & B X R & Mean \\
\hline Peluang (Opportunites) & & & & \\
\hline 1. Perkembangan teknologi informasi dan komunikasi & 0.44 & 4.00 & $0.28 / 4$ & $\mathbf{0 . 1 1}$ \\
\hline 2. Potensi kerjasama dengan jaringan pelaku pariwisata & 0.56 & 4.00 & $0.30 / 4$ & $\mathbf{0 . 1 4}$ \\
\hline 3. Trend Desa Wisata yang berkembang & 0.47 & 4.00 & $0.22 / 4$ & $\mathbf{0 . 1 2}$ \\
\hline 4. Pariwisata yang menjadi pengembangan prioritas NTT & 0.41 & 4.00 & $0.27 / 4$ & $\mathbf{0 . 1 0}$ \\
\hline 5. Minat masyarakat melakukan kegiatan wisata & 0.46 & 4.00 & $0.24 / 4$ & $\mathbf{0 . 1 2}$ \\
\hline 6. Penciptaan lapangan kerja bagi masyarakat setempat & 0.52 & 4.00 & $0.23 / 4$ & $\mathbf{0 . 1 3}$ \\
\hline Ancaman (Threats) & & & & \\
\hline 1. Bencana Alam seperti wabah penyakit & 0.09 & 4.00 & $0.28 / 4$ & $\mathbf{0 . 0 2}$ \\
\hline
\end{tabular}


Vol. 8 No 2, 2020

\begin{tabular}{lrrrc}
\hline 2. Persaingan objek wisata di tempat lain yang lebih kompetetif & 0.43 & 4.00 & $0.30 / 4$ & $\mathbf{0 . 1 1}$ \\
\hline 3. Masuknya budaya luar mengikis budaya lokal & 0.33 & 4.00 & $0.22 / 4$ & $\mathbf{0 . 0 8}$ \\
\hline $\begin{array}{l}\text { 4. Kebijakan internasional seperti travel warning ke destinasi } \\
\text { tertentu }\end{array}$ & 0.28 & 4.00 & $0.27 / 4$ & $\mathbf{0 . 0 7}$ \\
\hline TOTAL & $\mathbf{4 . 0 0}$ & & & $\mathbf{1 . 0 0}$ \\
\hline
\end{tabular}

Setelah mengetahui sintesa faktor-faktor kekuatan, kelemahan, kesempatan, dan ancaman, berikutnya pada tabel 3 dan 4 akan ditampilkan faktor-faktor strategis internal (IFAS) dan faktor-faktor strategis eksternal (EFAS).

Tabel 5 Faktor-Faktor Strategis Internal (IFAS)

\begin{tabular}{lccc}
\hline Faktor-Faktor Strategi Internal & Bobot & Rank & Skor \\
\hline Kekuatan (Strengths) & & & $\mathbf{0 . 2 4}$ \\
\hline 1. Keunikan dan Keaslian Budaya & 0.10 & $\mathbf{4 . 0 0}$ & $\mathbf{0 . 2 2}$ \\
\hline 2. Keindahan Panorama Alam & 0.08 & $\mathbf{3 . 5 0}$ & $\mathbf{0 . 2 7}$ \\
\hline 3. Keanekaragaman Flora dan Fauna & 0.12 & $\mathbf{4 . 0 0}$ & $\mathbf{0 . 3 8}$ \\
\hline 4. Keramahan Masyarakat Lokal & 0.10 & $\mathbf{4 . 0 0}$ & $\mathbf{0 . 1 9}$ \\
\hline 5. Keamanan Desa Pemo & 0.06 & $\mathbf{2 . 5 0}$ & $\mathbf{0 . 2 1}$ \\
\hline 6. Ketersediaan Amenitas berupa Homestay & 0.06 & $\mathbf{2 . 7 5}$ & $\mathbf{0 . 2 1}$ \\
\hline 7. Iklim yang sejuk membuat wisatawan betah & 0.08 & $\mathbf{3 . 5 0}$ & \\
\hline Kelemahan (Weakness) & & & $\mathbf{0 . 0 5}$ \\
\hline 1. Lemahnya kualitas SDM di bidang pariwisata & 0.07 & $\mathbf{3 . 0 0}$ & $\mathbf{0 . 2 1}$ \\
\hline 2. Jarak tempuh yang jauh dari pusat kota & 0.08 & $\mathbf{3 . 0 0}$ & $\mathbf{0 . 1 3}$ \\
\hline 3. Tempat makan dan minum yang kurang memadai & 0.06 & $\mathbf{2 . 0 0}$ & $\mathbf{0 . 0 2}$ \\
\hline 4. Akses jalan yang rusak & 0.07 & $\mathbf{2 . 7 5}$ & $\mathbf{0 . 3 3}$ \\
\hline 5. Kurangnya keterlibatan stakeholders & 0.06 & $\mathbf{2 . 5 0}$ & $\mathbf{0 . 1 6}$ \\
\hline 6. Kegiatan wisata yang belum terstruktur & 0.06 & $\mathbf{2 . 2 5}$ & $\mathbf{0 . 2 2}$ \\
\hline TOTAL & $\mathbf{1 . 0 0}$ & & $\mathbf{3 . 2 5}$
\end{tabular}

Tabel 6 Faktor-Faktor Strategis Eksternal (EFAS)

\begin{tabular}{|c|c|c|c|}
\hline Faktor-Faktor Strategi Eksternal & Bobot & Rank & Skor \\
\hline \multicolumn{4}{|l|}{ Peluang (Opportunites) } \\
\hline 1. Perkembangan teknologi informasi dan komunikasi & 0.11 & 3.50 & 0.39 \\
\hline 2. Potensi kerjasama dengan jaringan pelaku pariwisata & 0.14 & 3.50 & 0.49 \\
\hline 3. Trend Desa Wisata (pariwisata berbasis masyarakat) yang berkembang & 0.12 & 3.75 & 0.44 \\
\hline 4. Pariwisata yang menjadi pengembangan prioritas NTT & 0.10 & 3.25 & 0.33 \\
\hline 5. Minat masyarakat melakukan kegiatan wisata & 0.12 & 3.25 & 0.38 \\
\hline 6. Penciptaan lapangan kerja bagi masyarakat setempat & 0.13 & 3.75 & 0.49 \\
\hline \multicolumn{4}{|l|}{ Ancaman (Threats) } \\
\hline 1. Bencana Alam seperti wabah penyakit & 0.02 & 4.00 & 0.09 \\
\hline 2. Persaingan objek wisata di tempat lain yang lebih kompetetif & 0.11 & 1.25 & 0.14 \\
\hline 3. Masuknya budaya luar mengikis budaya lokal & 0.08 & 2.25 & 0.18 \\
\hline 4. Kebijakan internasional seperti travel warning ke destinasi tertentu & 0.07 & 2.50 & 0.17 \\
\hline TOTAL & 1.00 & & 3.10 \\
\hline
\end{tabular}

\section{Matrik Analisis SWOT Pengembangan Ekowisata Berbasis Masyarakat di Desa Pemo Taman Nasional Kelimutu}

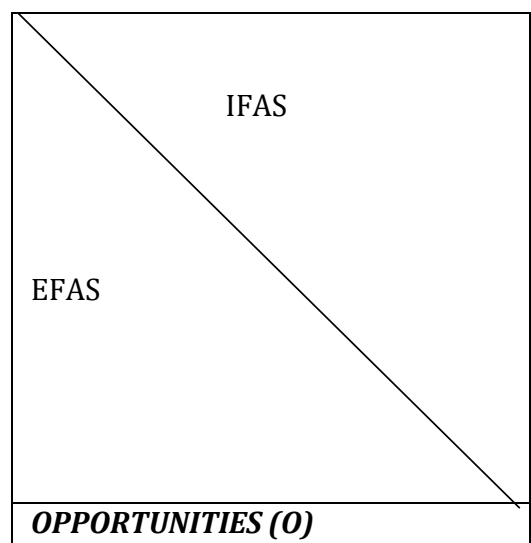

1. Perkembangan teknologi informasi dan komunikasi

\section{STRENGTHS (S)}

1. Keunikan dan Keaslian Budaya

2. Keindahan Panorama Alam

3. Keanekaragaman Flora dan Fauna

4. Keramahan Masyarakat Lokal

5. Keamanan Desa Pemo

6. Ketersediaan Amenitas berupa Homestay

7. Iklim yang sejuk membuat wisatawan betah

\section{STRATEGI SO}

1. Semakin meningkat dan melestarikan lingkungan serta keaslian aset yang ada.

\section{WEAKNESSES (W)}

1. Lemahnya kualitas SDM di bidang pariwisata

2. Jarak tempuh yang jauh dari pusat kota

3. Tempat makan dan minum yang kurang memadai

4. Akses jalan yang rusak

5. Kurangnya keterlibatan stakeholders

6. Kegiatan wisata yang belum terstruktur

\section{STRATEGI WO}

1. Meningkatkan sumber daya manusia.

2. Menyediakan sarana transportasi. 
2. Potensi kerjasama dengan jaringan pelaku pariwisata

3. Trend Desa Wisata (pariwisata berbasis masyarakat) yang berkembang

4. Pariwisata yang menjadi pengembangan prioritas NTT

5. Minat masyarakat melakukan kegiatan wisata

6. Penciptaan lapangan kerja bagi masyarakat setempat

\section{THREATS (T)}

1. Bencana Alam seperti wabah penyakit

2. Persaingan objek wisata di tempat lain yang lebih kompetetif

3. Masuknya budaya luar mengikis budaya lokal

4. Kebijakan internasional seperti travel warning ke destinasi tertentu

Sumber: Hasil Penelitian 2020
2. Menyediakan produk pariwisata yang dapat mendukung kegiatan pariwisata misal jajanan lokal.

3. Menjalin kerja sama dengan berbagai bidang dalam pemerintah.

4.Menyusun paket wisata yang dapat menarik.

5.Meningkatkan partisipasi dan peran masyarakat lokal dalam pembangunan pariwisata.
3. Melakukan kerja sama dengan

pemerintah daerah dan bebagai Lembaga Sosial Masyarakat (LSM).

4. Menyediakan kendaraan beroda dua sebagai salah satu alternatif transportasi.

5. Memanfaat perkembangan teknologi dan informasi.

\section{STRATEGI ST}

1. Memelihara keaslian dan keunikan budaya yang dimiliki. 2. Menjaga dan melestarikan keindahan alam.

3. Selalu menjaga dan membudayakan sapta pesona

4. Meningkatkan masyarakat maupun daerah.

5. Meningkatkan keramahan masyarakat lokal sehingga wisatawan semakin merasa nyaman dan betah.

\section{STRATEGI WT}

1. Meningkatkan pendidikan pengetahuan dan keterampilan.

2. Memanfaat sarana dan transportasi yang aman dan cepat 3 . Membangun serta menjaga fasilitas-fasilitas.

4. Memperbaiki akses jalan yang rusak.

5. Meningkatkan kreatifitas masyarakat.
Analisis SWOT Pengembangan Ekowisata Berbasis Masyarakat di Desa Pemo Taman Nasional Kelimutu

\begin{abstract}
a. Strategi Strength-Opportunity (S-0) dalam Pengembangan Ekowisata Berbasis Masyarakat di Desa Pemo Taman Nasional Kelimutu

Berdasarkan hasil tabulasi tabel S-O, maka strategi pengembangan Desa Pemo sebaiknya (1) Semakin meningkat dan melestarikan lingkungan serta keaslian yang ada sebagai aset budaya yang dimiliki oleh daerah. (2) Menyediakan produk pariwisata yang dapat mendukung kegiatan pariwisata dengan menyediakan jajanan lokal maupun kerajainan tangan lainnya sebagai lahan pencarian baru bagi masyarakat. (3) Menjalin kerja sama dengan berbagai bidang dalam pemerintah guna membangaun kebudayaan serta pemenfaatan keanekaragam flora dan fauna sebagai salah satu pendukung kegiatan pariwisata. (4) Menyusun paket wisata yang dapat menarik minat wisatan baik domestik maupun mancanegara. (5) Meningkatkan parisipasi dan peran masyarakat lokal dalam pembangunan pariwisata.
\end{abstract}

\section{b. Strategi Strength-Threat (S-T) dalam Pengembangan Ekowisata Berbasis Masyarakat di Desa Pemo Taman Nasional Kelimutu}

Berdasarkan tabulasi tabe S-T maka strategi pengembangan Desa Pemo harus: (1) Tetap memelihara keaslian dan keunikan budaya yang dimiliki. (2) Menjaga dan melestarikan keindahan alam agar turut mengurangi dampak buruk jika terjadi bencana alam. (3) Selalu menjaga dan membudayakan sapta pesona agar keanekaragaman potensi baik budaya maupun alam dapat terjaga dengan baik. (4) Meningkatkan pendapat masyarakat maupun pendapatan daerah dengan adanya kegiatan pariwisata. (5)
Meningkatkan keramahan masyarakat lokal sehingga wisatawan semakin merasa nyaman dan betah.

c. Strategi Weakness-Opportunity (W-0) dalam Pengembangan Ekowisata Berbasis Masyarakat di Desa Pemo Taman Nasional Kelimutu

Strategi W-O yaitu (1) Meningkatkan kualitas masyarakat setempat dengan pelatihan seperti pembuatan souvenir, bahasa inggris. (2) Jarak tempuh yang jauh dapat dimanfaat masyarakat lokal sebagai lahan pencarian dengan menyediakan sarana transportasi yang dapat mendukung kegiatan pariwisata. (3) Melakukan kerja sama dengan pemerintah daerah dan bebagai Lembaga Sosial Masyarakat (LSM) yang bergerak dalam bidang pariwisata dalam mengadakan fasilitas-fasilitas penunjang kegiatan pariwisata. (4) Akses jalan yang rusak dapat dapat dimanfaatkan oleh masyarakat lokal untuk menyediakan kendaraan beroda dua sebagai salah satu alternatif transportasi yang paling aman dan cepat guna mencapai tempat-tempat wisata yang berdekatan. (5) Memanfaat perkembangan teknologi dan informasi yang semakin moderan untuk semakin meningkat kretifitas.

d. Strategi Weakness-Threat (W-T) dalam Pengembangan Ekowisata Berbasis Masyarakat di Desa Pemo Taman Nasional Kelimutu

Terakhir, strategi pengembangan dalam rangka meminimalkan W-T yaitu: (1) Meningkatkan pendidikan pengetahuan dan keterampilan tentang keunikan yang dimiliki. (2) Memanfaat sarana dan transportasi yang aman dan cepat guna mencapai objek wisata jiks terjadi bencana. (3) Membangun serta menjaga fasilitas-fasilitas yang ada agar tetap terjaga keaslian. (4) Memperbaiki akses jalan yang rusak agar kegiatan pariwisata yang ada dapat berjalan dengan baik sehingga mendatangkan pendapatan serta 
Vol. 8 No 2, 2020

kesejahteraan bagi masyarakat. (5) meningkatkan kreatifitas masyarakat untuk menghasilkan suatu produk yang dapat mendukung kegiatan pariwisata.

\section{Penutup \\ Simpulan}

Berdasarkan hasil penelitian strategi pengembangan ekowisata berbasis masyarakat di Desa Pemo Kecamatan Kelimutu, TN Kelimutu, maka kesimpulan diambil yaitu Pertama, Desa Pemo memiliki potensi keaslian dan keunikan budaya. Keaslian ditandai dengan flora dan fauna khas Taman Nasional Kelimutu seperti Burung Garugiwa dan Kebun Kopi yang hanya tumbuh di Taman Nasional Kelimutu. Selain itu, daya tarik berupa sunset, lahan pertanian dan perkebunan warga juga menambah varian produk ekowisata berbasis masyarakat di Desa Pemo.

Kedua, Berdasarkan Analisis SWOT dengan langkah pertama yaitu melakukan analisis faktor internal dan eksternal kedalam IFAS dan EFAS menun jukkan tabel berada pada kuadrant berkembang agresif (kuadrant 1) dimana Desa Pemo berada pada posisi yang potensial untuk dikembangkan menggunakan daftar kekuatan internalnya guna manfaatkan peluang eksternal, mengatasi kelemahan internal dan menghindari ancaman eksternal. Adapun faktor-faktor kekuatan yang meliputi keunikan dan keaslian budaya, keindahan panorama alam keanekaragam flora dan fauna, lokasi yang strategi dan keramahan masyarakat lokal. Faktor kelemahan yang meliputi lemahnya sumberdaya manusia, jarak tempuh yang jauh, kuarang fasilitas, akses jalan yang rusak dan minimnya kreatifitas masyarakat. Sedangkan untuk faktor-faktor eksternalterbagai menjadi dua yaitu faktor peluang yang

\section{DAFTAR PUSTAKA/REFERENSI}

Dewi, M. H. U. (2013). Pengembangan desa wisata berbasis partisipasi masyarakat lokal di Desa Wisata Jatiluwih Tabanan, Bali. Jurnal Kawistara, 3(2)

Balai Taman Nasional Kelimutu (BTNK), 2013. Data Statistik Taman Nasional Kelimutu, Ende-Flores, Nusa Tenggara Timur. NTT: Balai TNK.

Damanik, Janianton and Helmut F. Weber. 2006. Perencanaan Ekowisata. Dari Teori ke Aplikasi. Pusat Studi Pariwisata (PUSPAR) UGM dan ANDI Press. Yogyakarta.

Fandeli, Chafid dan Muhammad Nurdin. 2005. Pengembangan Ekowisata Berbasis Konservasi di Taman Nasional. Fakultas Kehutanan UGM, Pusat Studi Pariwisata UGM, dan Kantor Kementerian Lingkungan Hidup. Yogyakarta.

Lewis, J. 2003. Design Issues. In Qualitative Research Practice: a Guide for Social Science Student Researcher (eds.) Jane Ritchie and Janes Lewis. London: SAGE Publications

Nistyantara, L. A. (2011). Strategi pengelolaan Taman Nasional Kelimutu melalui pendekatan Co-Management [tesis]. Bogor: Sekolah Pascasarjana, Institut Pertanian Bogo.r

Nugraha, Y. E. (2019). ANALISIS PASAR WISATAWAN MANCANEGARA PENGGUNA LAYANAN WISATA MEDIS DI BALI. Tourism-Jurnal Pariwisata, 2(2), 90-99.

Nugraha, Y. E., Paturusi, S. A., \& Wijaya, N. M. S. (2019). Kualitas Layanan Wisata Medis Yang Mempengaruhi Kepuasan dan Loyalitas Wisatawan Mancanegara Di Bali. Jurnal Master Pariwisata (JUMPA), 348-370.

Rangkuti F. 2006. Analisis SWOT Teknik Membedah Kasus Bisnis (Reorientasi Konsep Perencanaan Strategis untuk Menghadapi Abad 21). PT. Gramedia Pustaka Utama. Jakarta. meliputi: sektor pariwisata yang berkembang, menciptakan lapangan usaha bagi masyarakat, adanya jaringan kerja sama, berdekatan dengan objek lain dan perkembangan teknogi dan informasi. Faktor ancaman meliputi: persaingan antara objek wisata serupa terjadinya bencana alam, pengaruh budaya, pengaruh iklim dan politik. Dalam hal ini, pihak pengelolah dan pemerintah dapat bekerjasama dalam meminimalisirkan kelemahan kelemahan yang ada serta menghindari ancaman yang dapat membahayakan kelangsungan ekowisata berbasis masyarakat yang ada di Desa Pemo.

\section{Saran}

Terdapat beberapa saran yang diberikan merujuk pada hasil kajian strategi pengembangan ini berkaitan dengan strategi pengembangan ekowisata berbasis masyarakat di Desa Pemo yaitu sebagai berikut: (1) Pemerintah Kabupaten Ende terkususnya dinas pariwisata agar lebih memaksimalkan program yang mendukung pengembangan potensi-potensi yang ada di Kabupaten Ende secara baik dan berkelanjutan agar aset-aset yang dimiliki oleh daerah tetap terjaga kelestariannya. (2) Kepala Desa Pemo agar lebih memberikan perhatian yang lebih tinggi potensi-potensi yang ada di Desa Pemo memperbaiki sarana dan persarana desa agar dapat mendukung kegiatan pariwisata yang ada, guna mendatangkan kesejahteraan bagi masyarakat sekitarnya. (3) Masyarakat agar lebih memperkaya diri dengan dengan keterampilan serta menangkap peluangpeluang usaha dari kegiatan pariwisata yang ada di Desa Pemo dengan menyediakan produk-produk wisata yang dapat dirasakan oleh turis.

Suansri, P. (2003). Community based tourism handbook. Bangkok: Responsible Ecological Social Tour-REST.

Sugiyono. 2015. Metode Penelitian Manajemen: Pendekatan Kuantitatif, Kualitiatif, Kombinasi (mix methods), Penelitian Tindakan (Action Research), Penelitian Evaluasi. Bandung: Alfabeta.

Sunarjaya, I. G., Par, S., Par, M., Nugraha, Y. E., Kesos, S., \& Par, M. (2019, March). ANALISIS PERSEPSI EMPLOYEE EMPOWERMENT TERHADAP EMPLOYEE TURNOVER INTENTION DI DEWI SINTA HOTEL. In Journey (Journal of Tourismpreneurship, Culinary, Hospitality, Convention and Event Management) (Vol. 1, No. 1, pp. 182-206). 